Review

\title{
Ethical and Safety Issues of Stem Cell-Based Therapy
}

\author{
Vladislav Volarevic ${ }^{\circledR}$, Bojana Simovic Markovic ${ }^{1}$, Marina Gazdic ${ }^{2}$, Ana Volarevic ${ }^{1}$, Nemanja Jovicic ${ }^{3}$, \\ Nebojsa Arsenijevic ${ }^{1}$, Lyle Armstrong ${ }^{4}$, Valentin Djonov ${ }^{5}$, Majlinda Lako and Miodrag Stojkovic ${ }^{2}$
}

1. University of Kragujevac, Serbia, Faculty of Medical Sciences, Department of Microbiology and Immunology, Center for Molecular Medicine and Stem Cell Research;

2. University of Kragujevac, Serbia, Faculty of Medical Sciences, Department of Genetics;

3. University of Kragujevac, Serbia, Faculty of Medical Sciences, Department of Histology and Embryology;

4. Institute of Genetic Medicine, Newcastle University, UK;

5. Institute of Anatomy, University of Bern, Bern, Switzerland.

$\square$ Corresponding author: Prof. Vladislav Volarevic, Department of Microbiology and Immunology, Center for Molecular Medicine and Stem Cell Research, Faculty of Medical Sciences, University of Kragujevac, 69 Svetozar Markovic Street, 34000 Kragujevac, Serbia. Phone: +38134306800; fax: +38134306800 ext. 112. E-mail: drvolarevic@yahoo.com

(c) Ivyspring International Publisher. This is an open access article distributed under the terms of the Creative Commons Attribution (CC BY-NC) license (https://creativecommons.org/licenses/by-nc/4.0/). See http://ivyspring.com/terms for full terms and conditions.

Received: 2017.06.28; Accepted: 2017.10.11; Published: 2018.01.01

\begin{abstract}
Results obtained from completed and on-going clinical studies indicate huge therapeutic potential of stem cell-based therapy in the treatment of degenerative, autoimmune and genetic disorders. However, clinical application of stem cells raises numerous ethical and safety concerns.

In this review, we provide an overview of the most important ethical issues in stem cell therapy, as a contribution to the controversial debate about their clinical usage in regenerative and transplantation medicine.

We describe ethical challenges regarding human embryonic stem cell (hESC) research, emphasizing that ethical dilemma involving the destruction of a human embryo is a major factor that may have limited the development of hESC-based clinical therapies. With previous derivation of induced pluripotent stem cells (iPSCs) this problem has been overcome, however current perspectives regarding clinical translation of iPSCs still remain. Unlimited differentiation potential of iPSCs which can be used in human reproductive cloning, as a risk for generation of genetically engineered human embryos and human-animal chimeras, is major ethical issue, while undesired differentiation and malignant transformation are major safety issues.

Although clinical application of mesenchymal stem cells (MSCs) has shown beneficial effects in the therapy of autoimmune and chronic inflammatory diseases, the ability to promote tumor growth and metastasis and overestimated therapeutic potential of MSCs still provide concerns for the field of regenerative medicine.

This review offers stem cell scientists, clinicians and patient's useful information and could be used as a starting point for more in-depth analysis of ethical and safety issues related to clinical application of stem cells.
\end{abstract}

Key words: embryonic stem cells, induced pluripotent stem cells, mesenchymal stem cells, stem cell-based therapy.

\section{Introduction}

Stem cells have raised tremendous expectations among the medical doctors, researchers, patients, and the general public due to their capacity to differentiate into a broad range of cell types. Stem cell researchers are engaged in different endeavors, including treating genetic disorders and generating new stem cell-derived human tissues and biomaterials for use in pharmacy genomics and regenerative medicine.
Results obtained from completed and on-going clinical studies indicate huge therapeutic potential of stem cell-based therapy in the treatment of degenerative, autoimmune and genetic disorders $[1$, 2].

However, clinical application of stem cells raises some ethical and safety concerns. In this review we provide an overview of the most important ethical 
issues in stem cell research and therapy, as a contribution to the debate about their clinical use in regenerative and transplantation medicine. We describe and discuss ethical challenges regarding human embryonic stem cell (hESC) research, therapeutic potential and clinical translation of induced pluripotent stem cell (iPSC) and safety issues of mesenchymal stem cell (MSC)-based therapy.

Our hope is that stem cell scientists and clinicians will use the information presented herein as a starting point for more in-depth analysis of ethical and safety issues related to clinical translation of stem cells since controversial regulation and application of stem cell therapy has been falsely celebrated not only in countries with lax medical regulations but also in many developed countries. For instance, in 2016, 351 US businesses engaged in frequently unproven and direct-to-consumer marketing of different stem cell interventions was offered at 570 clinics [3].

\section{Ethical and safety concerns regarding hESC-based therapy}

hESCs are stem cells derived from the pluripotent inner cell mass of the pre-implantation embryos [4, 5]. hESCs express typical pluripotent stem cell markers such as octamer-binding transcription factor $3 / 4$ (OCT3/4), stage specific embryonic antigens 3 and 4 (SSEA-3 and SSEA-4), TRA-1-60, TRA-1-81 and alkaline phosphatase, possess high levels of telomerase activity and show normal karyotype [6, 7]. hESCs have capacity to differentiate into cell types of all three germ layers [endoderm, mesoderm, and ectoderm] under in vitro and in vivo conditions [6, 7]. Consequently, hESCs hold great promise in understanding of early human embryology and for developing the cell replacement strategies for the treatment of human diseases (Figure $1)$.

Nevertheless, the ethical dilemma involving the destruction of a human embryo was and remains a major factor that has slowed down the development of hESC-based clinical therapies.

The fundamental question is: Whether it is morally acceptable to pursue novel therapies for curing illnesses at the expense of destroying an early human embryo? This debate brings out individual opinions so deeply rooted in basic moral beliefs that developing a definitive policy acceptable to everyone seems unlikely. This ethical dilemma is portrayed in different legislation that exists throughout the world regulating hESCs research $[8,9]$. For example, in many countries including United Kingdom, it is illegal to perform nuclear transfer (NT) for reproductive or therapeutic purposes, while use of hESCs for research is allowed. Other countries retain more extreme stances, as is the case of Italy where there is a prohibition on all hESC-based research. On contrary, it is legal to use supernumerary in vitro

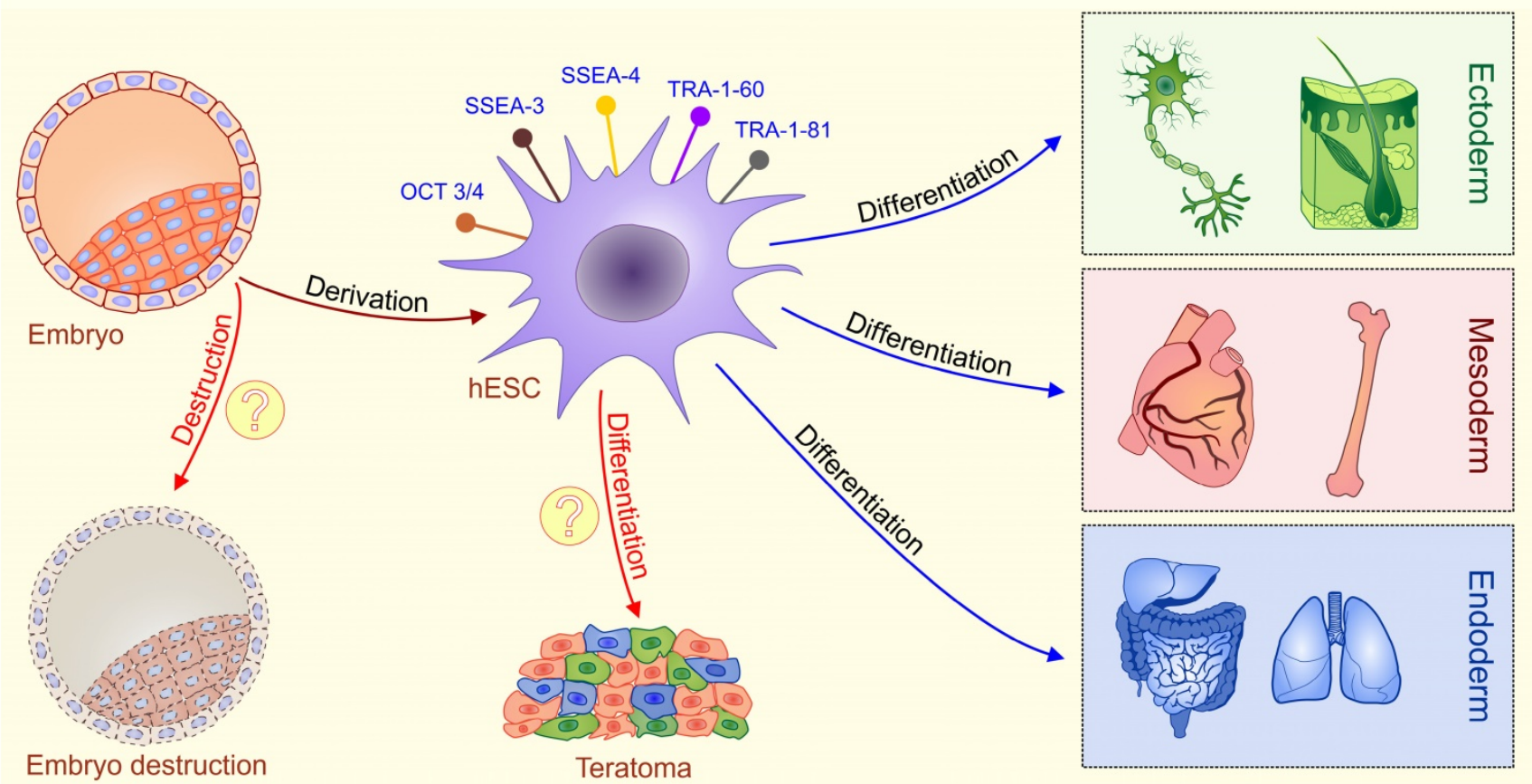

Figure 1. Schematic diagram describing characteristics of ESCs. Embryonic stem cells (ESCs) are harvested from a blastocyst. Embryonic stem (ES) cells are derived from the inner cell mass of the pre-implantation embryo. Fully characterized hESCs express typical pluripotent stem cell markers such as octamer-binding transcription factor 3/4 (OCT3/4), stage specific embryonic antigens 3 and 4 (SSEA-3 and SSEA-4), TRA-1-60, and TRA-1-81.These cells are pluripotent, meaning they can differentiate into cells from all three germ layers (ectoderm, mesoderm and endoderm). Main ethical issues (labeled with question marks): isolation of ESCs involves the destruction of a human embryo; transplantation of undifferentiated ESCs may result with a formation of teratomas, tumors that contain all three germ layers. 
fertilization (IVF)-derived embryos for derivation of new hESCs lines and to perform NT for the generation of patient-specific stem cells in the United Kingdom [10-12]. United States banned production of any hESCs line that requires the destruction of an embryo and research using hESCs lines is limited on usage of lines created prior to August 9, 2001. Present restrictions have additionally slowed the progress of hESCs technology and provide a significant barrier to the development of cell based clinical therapies. Additionally, the ethical debate surrounding the harvest of hESCs has made research on this topic controversial, and as a result, the majority of studies were focused on animal models [13].

It is important to highlight that beside ethical concerns, safety issues regarding hESC-based therapy are the main problem for their clinical use. The pluripotency of hESCs is a double-edged sword; the same plasticity that permits hESCs to generate hundreds of different cell types also makes them difficult to control after in vivo transplantation [14]. When undifferentiated hESCs are transplanted, teratomas, tumors that contain all three germ layers, could develop [Figure 1] [15]. Studies have revealed that appearance of teratoma is between $33-100 \%$ in hESC-transplanted immunodeficient mice, depending on the implantation site, cell maturation, purity, and implantation techniques $[16,17]$.

Currently, the only way to ensure that teratoma will not develop after hESC transplantation is to differentiate them in desired and mature cell type before injection and screen them for the presence of undifferentiated cells. When such procedures were rigorously followed, teratomas were not observed in over 200 animals transplanted with hESC-derived cardiomyocytes [18]. However, unwanted and uncontrolled differentiation of hESCs was still noticed despite following up of this procedure. Primitive population of nestin+ neuroepithelial cells, that continued to proliferate in the striatum, was noticed in rats with Parkinson disease, 70 days after transplantation of hESC-derived dopamine neurons [19]. This raises a cautionary flag and suggests that even committed progenitors can proliferate excessively after transplantation, a problem that may be solved by improving purification methods.

However, despite these safety concerns, recently published data [20] suggest that under controlled conditions, hESC-derived cells could serve as a potentially safe new source in regenerative medicine.

Clinical trial that investigates potential of hESC-based therapy for the treatment of diabetes mellitus is opened and recruitment of patients has begun in 2014 [21]. The goal of this study is to evaluate the safety and efficacy of VC-01, an implant containing hESCs derived pancreatic progenitor cells encapsulated by an immune protecting device, which would allow the cells to proliferate and differentiate into mature $\beta$-cells in vivo without the possibility of immune rejection [22].

Recently, Song and co-workers [20], reported that subretinal transplantation of hESC-derived retinal pigment epithelial cells (hESC-RPE) in four Asian patients: two with dry age-related macular degeneration and two with Stargardt macular dystrophy was safe and well tolerated procedure. Visual acuity improved 9-19 letters in three patients and remained stable [ +1 letter] in one patient. During one year follow-up period, serious safety issues related to the transplanted cells such as: adverse proliferation, tumorigenicity, ectopic tissue formation, was not observed. Based on these encouraging results, during the past few years, several clinical trials are investigating therapeutic potential of hESC-RPE in patients with Stargardt macular dystrophy and advanced dry age related macular degeneration (Table 1, left panel) and promising results are expecting in next year.

\section{Advances and challenges of iPSC technology}

iPSC are very similar to hESCs in terms of karyotype, phenotype, telomerase activity and capacity for differentiation. However, iPSCs are considered morally superior to hESCs since their generation does not require destruction of embryos [23]. Takahashi and Yamanaka demonstrated the first direct reprogramming of mammalian somatic cells [24]. Up-regulation of "Yamanaka factors": sex determining region $\mathrm{Y}$ box-containing gene 2 [SOX2], OCT3/4, tumor suppressor Krüppel-like factor 4 [KLF4], and proto-oncogene $c-M Y C$ managed to reprogram differentiated somatic cells in the pluripotent state [24].

Since then, iPSCs technology provides a historic opportunity to move away from embryo destruction and opened a new era of personalized medicine. Patient-specific iPSCs may be helpful in drug screening, generating in vitro models of human diseases, and novel reproductive techniques (Figure 2). In vitro, patient-specific iPSCs can differentiate to specific cell types which enable testing of new drugs in patient-specific conditions. Since iPSC-derived cells are generated from somatic cells previously obtained from a patient, there is no risk of immune rejection after their transplantation [25]. The development of reproductive technology enables generation of gametes (sperm and eggs) from human iPSCs [26]. This technique could be helpful for treating infertility, however, the use of iPSC-derived gametes raises set of 
ethical concerns related to the potential exploitation of created embryos, human NT, and risk of change natural reproduction including the possibility to derive gametes for same-sex reproduction, as well as in the asexual reproduction [26].

Table 1. Clinical trials using hESC-RPE and iPSC-derived cells

\begin{tabular}{|c|c|c|c|}
\hline \multicolumn{2}{|l|}{ hESC-RPE cellular therapy } & \multicolumn{2}{|l|}{ iPSC-derived cells in clinical trials } \\
\hline Condition & $\begin{array}{l}\text { ClinicalTrials.gov Identifier } \\
\text { number/ Phase/ Status }\end{array}$ & Condition & $\begin{array}{l}\text { ClinicalTrials.gov Identifier number/ } \\
\text { Source/ Status }\end{array}$ \\
\hline $\begin{array}{l}\text { Age Related Macular } \\
\text { Degeneration, Stargardt's Disease, } \\
\text { Exudative Age-related, Macular } \\
\text { Degeneration }\end{array}$ & $\begin{array}{l}\text { NCT02903576/ I/II/ study is } \\
\text { currently recruiting participants }\end{array}$ & Leukemia, Lymphoma & $\begin{array}{l}\text { NCT02564484/ blood/ study is } \\
\text { currently recruiting participants }\end{array}$ \\
\hline $\begin{array}{l}\text { Dry Age Related Macular } \\
\text { Degeneration }\end{array}$ & $\begin{array}{l}\text { NCT01344993/ I/II/ study has been } \\
\text { completed }\end{array}$ & Ataxia-Telangiectasia (A-T) & $\begin{array}{l}\text { NCT02246491/ blood, skin/ study is } \\
\text { currently recruiting participants }\end{array}$ \\
\hline Stargardt's Macular Dystrophy & $\begin{array}{l}\text { NCT01345006/ I/II/ study has been } \\
\text { completed }\end{array}$ & Chronic Granulomatous Disease & $\begin{array}{l}\text { NCT02926963/ hair, skin/ study is } \\
\text { currently recruiting participants }\end{array}$ \\
\hline $\begin{array}{l}\text { Dry Age-related Macular } \\
\text { Degeneration }\end{array}$ & $\begin{array}{l}\text { NCT03046407/ early } 1 / \text { study is } \\
\text { currently recruiting participants }\end{array}$ & Retinoblastoma & $\begin{array}{l}\text { NCT02193724/ skin, blood/ study is } \\
\text { currently recruiting participants }\end{array}$ \\
\hline Stargardt's Macular Dystrophy & $\begin{array}{l}\text { NCT01469832/ I/II/ study has been } \\
\text { completed }\end{array}$ & Autism Spectrum Disorder & $\begin{array}{l}\text { NCT02720939/ blood/ study is } \\
\text { currently recruiting participants }\end{array}$ \\
\hline $\begin{array}{l}\text { Dry Macular Degeneration, } \\
\text { Geographic Atrophy }\end{array}$ & $\begin{array}{l}\text { NCT02590692/ I/II/ study is } \\
\text { currently recruiting participants }\end{array}$ & Ectodermal Dysplasia & $\begin{array}{l}\text { NCT02896387/ skin, cornea/ study is } \\
\text { currently recruiting participants }\end{array}$ \\
\hline $\begin{array}{l}\text { Dry Age-related Macular } \\
\text { Degeneration }\end{array}$ & $\begin{array}{l}\text { NCT02755428/ early } 1 / \text { study is } \\
\text { currently recruiting participants }\end{array}$ & \multirow{4}{*}{$\begin{array}{l}\text { Intellectual Deficiency, Asymptomatic } \\
\text { Carrier of the Mutation of the Gene } \\
\text { MYT1L, Healthy Volunteers }\end{array}$} & \\
\hline $\begin{array}{l}\text { Macular Degeneration, } \\
\text { Stargardt's Macular Dystrophy }\end{array}$ & $\begin{array}{l}\text { NCT02749734/ I/ study is currently } \\
\text { recruiting participants }\end{array}$ & & \multirow[t]{3}{*}{$\begin{array}{l}\text { NCT02980302/ skin/ study is } \\
\text { currently recruiting participants }\end{array}$} \\
\hline $\begin{array}{l}\text { Age-related Macular } \\
\text { Degeneration }\end{array}$ & $\begin{array}{l}\text { NCT02286089/ I/II/ study is } \\
\text { currently recruiting participants }\end{array}$ & & \\
\hline $\begin{array}{l}\text { Age-related Macular } \\
\text { Degeneration }\end{array}$ & $\begin{array}{l}\text { NCT03102138/ I/ study is currently } \\
\text { recruiting participants }\end{array}$ & & \\
\hline
\end{tabular}

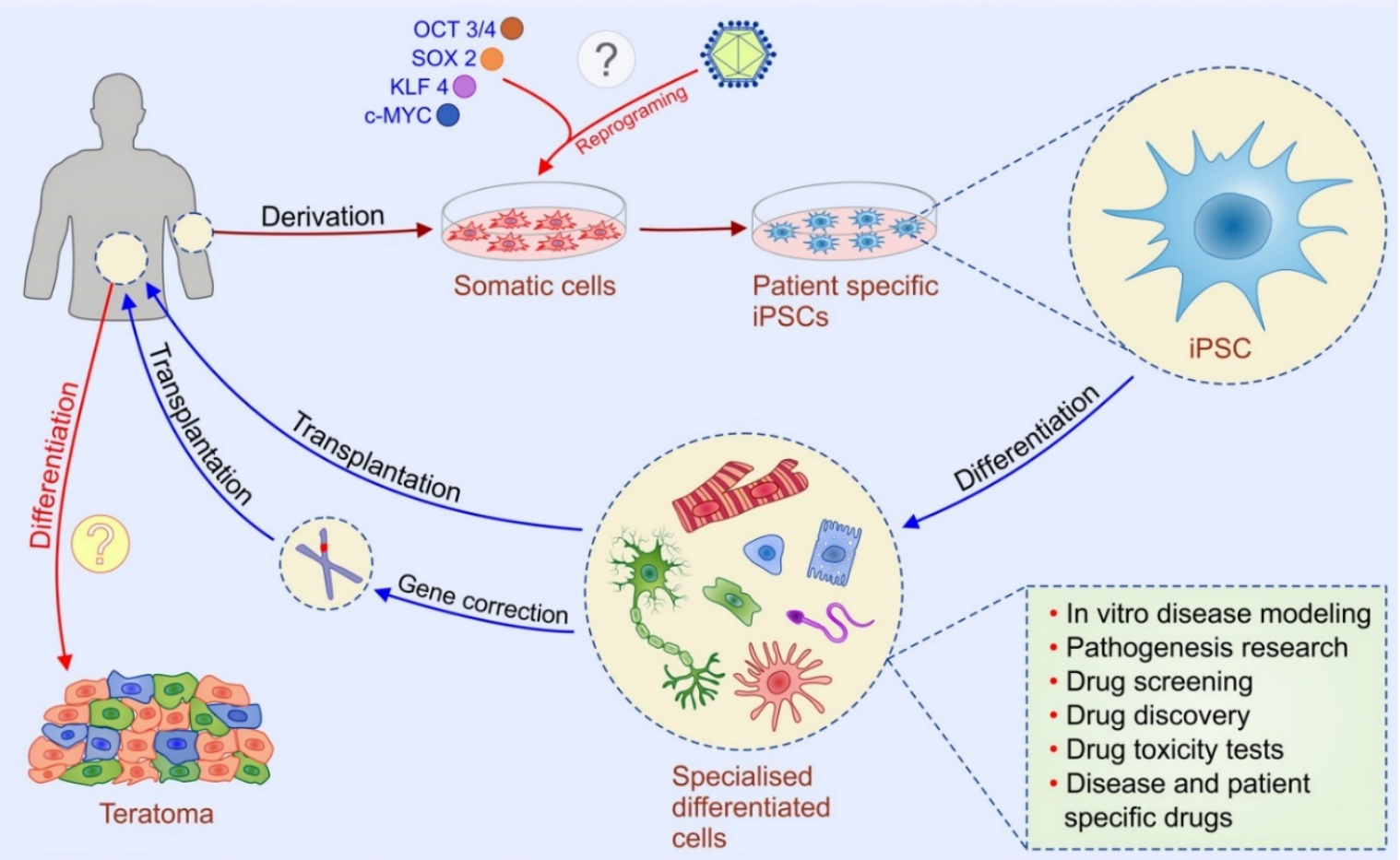

Figure 2. Potential applications of human induced pluripotent stem cells (iPSCs). iPSC technology can be potentially utilized in disease modeling, drug discovery, gene therapy, and cell replacement therapy. Genetic mutations can be corrected by gene targeting approaches before or after reprogramming. iPSCs are considered morally superior then ESCs since their generation do not require destruction of embryos. Introduction of the four transcription factors-" Yamanaka factors" (Oct-4, Sox-2, KIf-4, and c-Myc) leads to reprogramming of a somatic cell to an iPSC which can further differentiate into different types of cells. Two types of methods for the delivery of reprogramming factors into the somatic cells can be used: integrating viral vector systems and non-integrating methods. The main safety issue regarding iPSC-based therapy (labeled with question marks) is the risk of teratoma formation which might happen if patient receive iPSC-derived cells that contain undifferentiated iPSC and dilemma whether retroviral and lentiviral-free iPSC are safe for clinical application. 
As for hESCs the main safety issue regarding iPSC-based therapy is the risk of teratoma formation which can happened if patient receive iPSC-derived cells that contain undifferentiated iPSC (Figure 2). Uncontrolled proliferation and differentiation of transplanted undifferentiated iPSCs may result in generation of tumors and/or undesired differentiation of iPSCs in broad range of somatic cells [27]. Thus, development of more effective methods for generation of purified populations of autologous iPSC-derived differentiated cells remains a challenge for personalized and regenerative medicine [28].

It is important to highlight here that due to the genomic instability of iPSCs [29], even improved protocols for their differentiation, does not guarantee safe clinical application and underlines several differences compared to hESCs [30-32].

Transformation of iPSCs into tumor cells could be a consequence of oncogenic properties of the reprogramming cocktail (use of c-MYC) [33], or insertional mutagenesis induced by the reprogramming with integrating retroviral or lentiviral vectors which disrupts endogenous genes [34]. Recently, clinical trial that investigated potential of autologous iPSC-RPE for the treatment of advanced neovascular age-related macular degeneration has been stopped [35]. Although transplantation of iPSC-RPE in the first enrolled patient was well tolerated after one year follow-up, study was stopped when it moved on to a possible second patient. Since iPSC, derived from second patient contained mutation, they did not pass a genomic validation step and the team led by Takahashi decided to at least temporarily suspend the trial. However, what remains unclear at this time and what should be explored is whether the mutation in the second patient's iPSC was pre-existing in the patient's fibroblasts or it occurred during the reprogramming process itself.

In order to make the transition of iPSC-based therapy from lab to clinic, recently conducted research studies are focusing on identifying new molecular strategies that can increase cell reprogramming efficiency without causing genetic and epigenetic abnormalities in the iPSCs [36]. Several types of non-integrating methods have been developed [use of non-integrating adenoviral vectors, repeated transfection of plasmids, Cre-loxP-mediated recombination, PiggyBac-transposition] [37-41].

Unfortunately, there is still insufficient data to argue that these retroviral and lentiviral-free iPSC are safe for clinical application (Figure 2). Accordingly, further in vitro and in vivo, animal, studies are necessary to develop optimized growth and differentiation protocols and reliable safety assays to evaluate the potential of iPSCs and iPSC-derived differentiated cells for clinical application in patients.

Several clinical trials that are going to explore clinical potential of iPSC-derived cells are currently recruiting patients (Table 1 , right panel) and scientific and public community curiously expects these results.

\section{Mesenchymal stem cells: key players in the cell-based therapy of immune-mediated diseases}

Mesenchymal stem cells are adult, fibroblast-like, multipotent cells, most frequently isolated from bone marrow (BM), adipose tissue (AT) and umbilical cord blood (UCB) [42]. The International Society for Cellular Therapy formulated minimal criteria for uniform characterization of MSCs such as plastic adherence, potential for differentiation in osteogenic, chondrogenic, and adipogenic lineage, cell surface expression of CD105, CD73, CD90 and the absence of hematopoietic markers CD45, CD34, CD14 or CD11b, CD79a or CD19 and HLA-DR (Figure 3) [43].

These cells can differentiate into a variety of cell types of mesodermal origin and due to their plasticity, some studies [44-46] claim that MSCs can differentiate towards cells of neuro-ectodermal (neurons, astrocytes, and oligodendrocytes) or endodermal (hepatocytes) origin [47]. In addition to their differentiation potential, MSCs possess broad spectrum of immuno-modulatory capacities [48]. MSCs 'primed' by pro-inflammatory cytokines (interferon gamma and tumor necrosis factor alpha) adopt immunosuppressive phenotype, and through cell-to-cell contact (engagement of the inhibitory molecule programmed death 1 with its ligands) or through the production of soluble factors (transforming growth factor- $\beta$ (TGF- $\beta$ ), interleukin (IL)-10, hepatocyte growth factor (HGF), prostaglandin E2, nitric oxide, indoleamine 2,3 dioxygenase and heme-oxygenase-1) modulate the adaptive and innate immune response [42, 49]. In addition, MSCs lack the expression of membrane bound molecules involved in immune rejection which enable their allogenic transplantation [50].

Accordingly, the past decade has witnessed an outstanding scientific production focused towards the possible clinical applications of MSCs in the therapy of autoimmune and chronic inflammatory diseases including inflammatory bowel diseases (IBD), liver disorders and cardiac diseases with very encouraging results (Figure 3) [51-70]. 


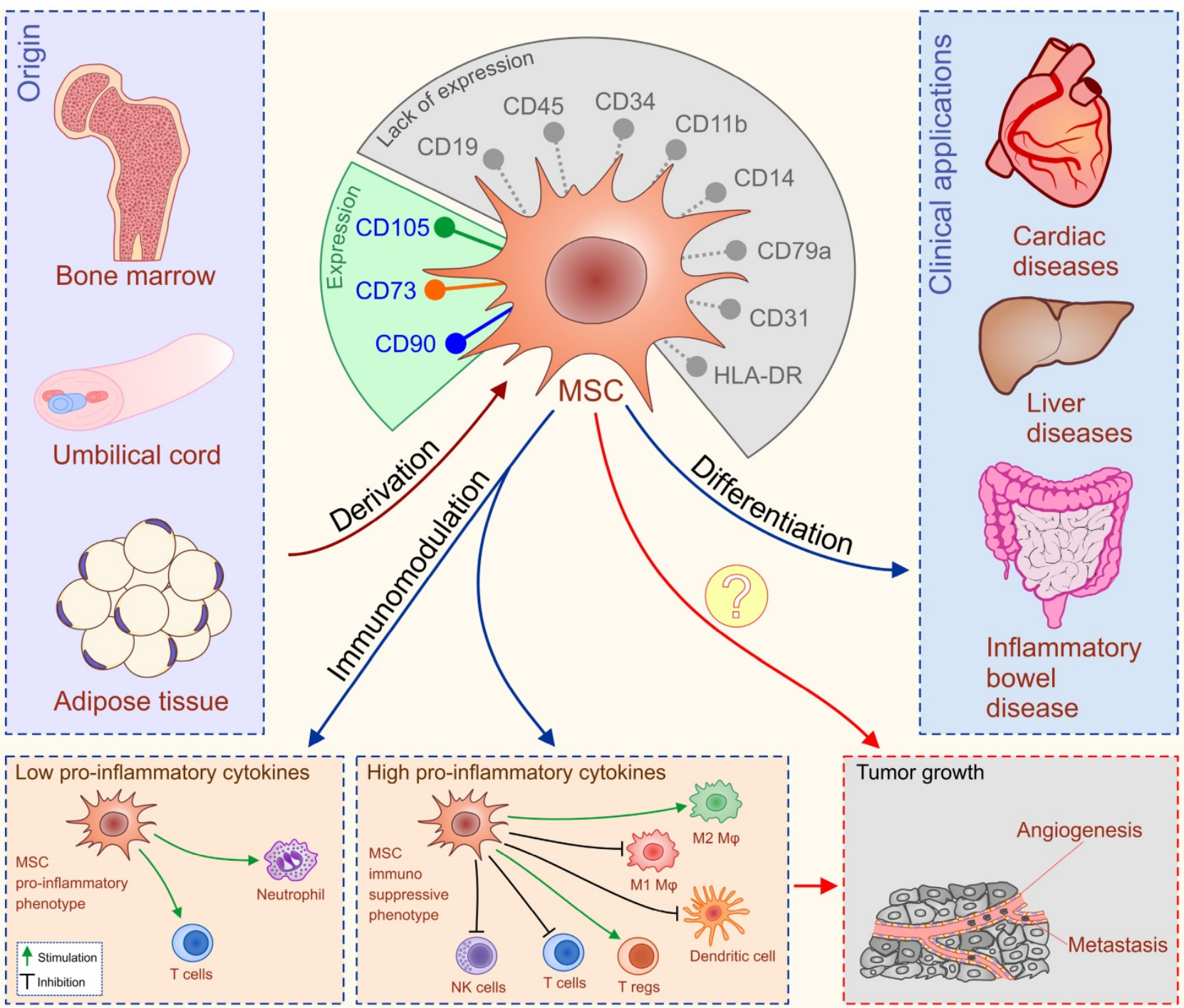

Figure 3. Differentiation ability and immune-modulatory characteristics of MSCs. MSCs are adult, fibroblast-like, multipotent cells, most frequently isolated from bone marrow (BM), adipose tissue (AT) and umbilical cord blood (UCB). Minimal criteria for characterization of MSCs are: cell surface expression of CD 105, CD73, CD90 and the absence of hematopoietic markers CD45, CD34, CD14 or CD 1 b, CD79 $\alpha$ or CD 19 and HLA-DR. MSCs have been applied clinically in patients with inflammatory bowel diseases (IBD), liver disorders and cardiac diseases with very encouraging results. MSCs possess broad spectrum of immuno-modulatory capacities. Serious adverse events noticed in some of MSC-treated patients could be explained by the fact that MSCs either suppress or promote inflammation in dependence of inflammatory environment to which they are exposed to. The primary concerns for clinical application of MSCs (labeled with question marks) are unwanted differentiation of the transplanted MSCs and their potential to suppress anti-tumor immune response and generate new blood vessels that may promote tumor growth and metastasis.

\section{MSCs in IBD therapy}

Instantly, there are two routes for the administration of MSCs in IBDs patients: intravenous administration for the systemic control of intestinal inflammation in the therapy of luminal Chron's disease (CD) and ulcerative colitis (UC), and the local administration as a therapeutic approach for patients with perianal fistulazing CD [51-58]. Administration of autologous or allogeneic MSCs derived from BM and AT achieved significant clinical efficacy in patients with fistulazing $\mathrm{CD}$ by attenuating local immune response and by promoting tissue repair [51-58].
Results obtained in huge number of clinical trials [51-55] indicate that local application of autologous and allogeneic BM-MSCs and AT-MSCs are simple, safe, and beneficial therapy for the treatment of perianal fistulas in $\mathrm{CD}$ patients with no adverse effects. On contrary, adverse effects have been reported in three of nine improved clinical trials [56] that investigated therapeutic potential of intravenously injected MSCs.

Study conducted by Duijvestein and coworkers [56] documented that 6 weeks after MSCs treatment, three patients required surgery due to disease worsening. Similar results were noticed in another clinical trial [57]. In this study, autologous MSCs, 
derived from marrow aspirate and propagated for 2-3 weeks with fibrinogen depleted human platelet lysate, were administered to IBD patients. Twelve patients received single MSCs intravenous infusion of 2, 5 or 10 million cells/ $\mathrm{kg}$ and serious adverse events were seen in seven patients. Aggravation of disease was noticed in five patients while adverse events in other two patients were possibly related to the infusion of MSCs [57].

Moreover, serious side effects were seen in patients with moderate to severe UC that received Multistem (stem cells derived from adult BM and non-embryonic tissue sources) as potentially new therapeutic agent for the treatment of UC [58].

Serious adverse events noticed in some of MSC-treated patients could be explained by the fact that MSCs either suppress or promote inflammation in dependence of inflammatory environment to which they are exposed to [59]. When MSCs are transplanted in the tissue with high levels of pro-inflammatory cytokines (IFN- $\gamma$, TNF- $\alpha$, IL-12, IL-6, IL-17 and IL-23), MSCs adopt an immuno-suppressive phenotype and modify maturation of DCs, promote conversion of macrophages in anti-inflammatory M2 phenotype and suppress proliferation and activation of $\mathrm{T}$ lymphocytes, NK and NKT cells. In the presence of low levels of inflammatory cytokines, MSCs adopt a pro-inflammatory phenotype and produce inflammatory cytokines that promote neutrophil and $\mathrm{T}$ cell activation and enhance immune response and inflammation [59].

\section{MSC-based therapy of liver diseases}

Over the past few years, several clinical trials used MSCs to treat patients with liver diseases [60-65]. Obtained results demonstrated that MSCs treatment improved liver function in safe and well tolerated manner [60-65]. Amer and colleagues demonstrated the safety and short-term therapeutic effect of autologous transplantation of bone marrow MSCs-derived hepatocyte-like cells in patients with end-stage liver failure [61]. In patients with liver failure caused by hepatitis B virus infection, autologous transplantation of BM-MSCs provided short-term efficacy in respect to several clinical and biochemical parameters, but long-term outcomes were not markedly improved [62]. Recent studies reported that infusion of umbilical cord-derived MSCs was well tolerated in patients with decompensated cirrhosis, and in patients suffering from acute on chronic liver failure, resulting in significant improvement of liver function and increased survival rates $[64,65]$.
MSCs as a promising tool in the therapy of cardiac diseases

Several studies have examined therapeutic potential of autologous and allogeneic MSCs in the treatment of acute myocardial infarction (MI) [66-70]. In a phase I clinical study [66], 53 patients were randomized to receive either allogeneic MSCs or placebo, 7 to 10 days after MI. An improvement of overall clinical status was noticed 6 months after intravenous infusion of MSCs. Chen and colleagues [67] administered autologous MSCs intra-coronary in patients with subacute MI and observed decreased perfusion defect, improved left ventricular ejection fraction, and left ventricular remodeling 3 months after therapy.

Currently, there are several published or ongoing clinical trials that demonstrated beneficent effects of MSC-based therapy in the treatment of chronic ischemic cardiomyopathy. Injection of MSCs attenuated fibrosis, induced neo-angiogenesis, enhanced contractility, and improved the quality of life of patients with chronic ischemic cardiomyopathy [66-70]. Additionally, it was reported that intracoronary transplantation of autologous MSCs reduced episodes of tachycardia in patients with chronic ischemic cardiomyopathy and implanted cardioverter defibrillator [69]. Haack-Sørensen and co-workers performed demonstrated that intra-myocardial injections of autologous MSC significantly improve quality of life, physical limitation and angina stability of patients with chronic coronary artery disease and refractory angina [70].

\section{The other side of the coin: safety issues regarding MSCs-based therapy}

Despite these promising results, safety issues regarding MSCs-based therapy are still a matter of debate, especially in the long-term follow up. The primary concern is unwanted differentiation of the transplanted MSCs and their potential to suppress anti-tumor immune response and generate new blood vessels that may promote tumor growth and metastasis.

MSCs have a potential to differentiate into undesired tissues, including bone and cartilage. Encapsulated structures were found in the infarcted areas of myocardium after transplantation of MSCs. The structures contained calcifications or ossifications [71]. Study conducted by Yoon et colleagues showed that transplantation of unfractionated BM-derived cells into acutely infarcted myocardium may induce development of intra-myocardial calcification [72].

It was recently reported that three women suffering from macular degeneration, within a week 
of undergoing "adipose tissue stem cell"-based therapy developed complications including vision loss, detached retinas and bleeding and are now totally blind and unlikely to recover [73]. The treatment involved combining fat tissue removed from the patients' abdomens with enzymes to obtain "adipose-derived" stem cells. These were mixed with blood plasma containing large numbers of platelets and injected into the women's eyes. Although, usually experimental eye procedures are tested on one eye first so that if something goes wrong the patient is still able to see with the other eye, in this trial both eyes were treated at once which, at the end, resulted with complete blindness in these patients.

These results suggest that local microenvironment in which MSCs engraft contains factors that induce unwanted differentiation of transplanted MSCs in vivo. Therefore, new research studies should be focused in definition of factors and signaling pathways that are responsible for the fate of MSCs after their in vivo administration.

In addition to unwanted differentiation, MSCs may bridge the gap between anti-tumor immune response and neo-angiogenesis in malignant diseases, thus promoting tumor growth and metastasis. After injection, MSCs migrate towards primary tumors [74] where due to their immuno-modulatory characteristics; suppress anti-tumor immune response resulting with an increased tumor growth $[75,76]$. We showed that injection of human MSCs promotes tumor growth and metastasis in tumor bearing mice, which was accompanied by lower cytotoxic activity of $\mathrm{NK}$ and CD8+ T cells and increased presence of immuno-suppressive IL-10 producing T lymphocytes and CD4+Foxp3+ $\mathrm{T}$ regulatory cells [77]. MSCs promote polarization of immune response towards anti-inflammatory Th2 pathway creating an immunosuppressive environment which enables progression of tumor growth and metastasis [77].

Additionally, MSCs promote metastasis by enhancing generation of new blood vessels. MSCs have the capacity to differentiate into endothelial cells and to create a capillary network [78, 79]. Injected MSCs migrate to the metastatic sites [74] and produce pro-angiogenic factors: vascular endothelial growth factor, basic fibroblast growth factor, TGF- $\beta$, platelet-derived growth factor, angiopoietin-1, placental growth factor, IL-6, monocyte chemotactic protein-1, HGF, resulting with neo-vascularization [80].

\section{Conclusions}

The creation and clinical use of hESCs have long been the unique focus of stem cell ethics. Current ethical controversies regarding stem cell-based therapy are focused on the unlimited differentiation potential of iPSCs which can be used in human cloning, as a risk for generation of human embryos and human-animal chimeras.

Since undesired differentiation and malignant transformation are major safety issues regarding transplantation of iPSCs and iPSC-derived cells, protocols for differentiation of iPSCs should be optimized in order to ensure the purity of iPSC-derived populations of differentiated cells before their clinical use. Considering the fact that MSCs are frequently and worldwide offered as universal human remedy but may promote tumor growth and metastasis, studies which utilize MSCs should be focused in continuous monitoring and long-term follow-up of MSC-treated animal models in order to determine possible pro-tumorigenic and other detrimental effects of MSC-based therapy.

\section{Abbreviations}

hESC: human embryonic stem cell; iPSCs: induced pluripotent stem cells; MSCs: mesenchymal stem cells; OCT3/4: octamer-binding transcription factor $3 / 4$; SSEA-3 and SSEA-4: stage specific embryonic antigens 3 and 4; NT: nuclear transfer; IVF: in vitro fertilization; hESC-RPE: retinal pigment epithelial cells; BM: bone marrow; AT: adipose tissue; UCB: umbilical cord blood; TGF- $\beta$ : transforming growth factor- $\beta$; IL: interleukin; HGF: hepatocyte growth factor; IBD: inflammatory bowel diseases; CD: Chron's disease; UC: ulcerative colitis; MI: myocardial infarction.

\section{Acknowledgment}

This study was supported by "Start Up for Science" grant funded by Phillip Morris and Center for Leadership Development, Swiss National Science Foundation project (SCOPES IZ73Z0_152454/1), Serbian Ministry of Science (ON175069 and ON175103) and Faculty of Medical Sciences University of Kragujevac (MP01/14 and MP01/12). Lako holds an ERC fellowship (614620).

\section{Competing Interests}

The authors have declared that no competing interest exists.

\section{References}

1. Volarevic V, Ljujic B, Stojkovic P, et al. Human stem cell research and regenerative medicine: present and future. Br Med Bull. 2011; 99:155-168.

2. Volarevic V, Erceg S, Bhattacharya SS, et al. Stem cell-based therapy for spinal cord injury. Cell Transplant. 2013; 22:1309-1323.

3. Turner L and Knoepfler P. Selling Stem Cells in the USA: Assessing the Direct-to-Consumer Industry. Cell Stem Cell. 2016; 19:154-157.

4. Smith AG. Embryo-derived stem cells: of mice and men. Annu Rev Cell Dev Biol. 2001; 17:435-462.

5. Zhang $X$, Stojkovic P, Przyborski S, et al. Derivation of human embryonic stem cells from developing and arrested embryos. Stem Cells. 2006; 24:2669-2676. 
6. Thomson JA, Itskovitz-Eldor J, Shapiro SS, et al. Embryonic stem cell lines derived from human blastocysts. Science. 1998; 28:1145114-1145117.

7. Reubinoff BE, Pera MF, Fong CY, et al. Embryonic stem cell lines from human blastocysts: somatic differentiation in vitro. Nat Biotechnol. 2000; 18:399-404.

8. De Trizio E and Brennan CS. The business of human embryonic stem cell research and an international analysis of relevant laws. J Biolaw Bus. 2004; $7 \cdot 14-22$

9. International Society for Stem Cell Research. Stem cell policies by country. Available at: http://www.isscr.org/public/regions/index.cfm. Accessed April 11, 2008.

10. Stojkovic M, Stojkovic P, Leary C, et al. Derivation of a human blastocyst after heterologous nuclear transfer to donated oocytes. Reprod Biomed Online. 2005; 11:226-231.

11. Stojkovic M, Lako M, Stojkovic P, et al. Derivation of human embryonic stem cells from day- 8 blastocysts recovered after three-step in vitro culture. Stem Cells. 2004; 22:790-797.

12. Heng BC, Tong GQ, Stojkovic M. The egg-sharing model for human therapeutic cloning research: managing donor selection criteria, the proportion of shared oocytes allocated to research, and amount of financial subsidy given to the donor. Med Hypotheses. 2006; 66:1022-1024.

13. Godfrey KJ, Mathew B, Bulman JC, et al. Stem cell-based treatments for Type 1 diabetes mellitus: bone marrow, embryonic, hepatic, pancreatic and induced pluripotent stem cells. Diabet Med. 2012; 29:14-23.

14. Nussbaum J, Minami E, Laflamme MA, et al. Transplantation of undifferentiated murine embryonic stem cells in the heart: teratoma formation and immune response. FASEB J. 2007; 21:1345-1357.

15. Murry CE and Keller G. Differentiation of embryonic stem cells to clinically relevant populations: lessons from embryonic development. Cell. 2008; 132:661-680

16. Kroon E, Martinson LA, Kadoya K, et al. Pancreatic endoderm derived from human embryonic stem cells generates glucose-responsive insulin-secreting cells in vivo. Nat Biotechnol. 2008; 26:443-452.

17. Prokhorova TA, Harkness LM, Frandsen U, et al. Teratoma formation by human embryonic stem cells is site dependent and enhanced by the presence of Matrigel. Stem Cells Dev. 2009; 18:47-54

18. Laflamme MA, Gold J, Xu C, et al. Formation of human myocardium in the rat heart from human embryonic stem cells. Am J Pathol. 2005; 167:663-671.

19. Roy NS, Cleren C, Singh SK, et al. Functional engraftment of human ES cell-derived dopaminergic neurons enriched by coculture with telomerase-immortalized midbrain astrocytes. Nat Med. 2006; 12:1259-1268.

20. Song WK, Park KM, Kim HJ, et al. Treatment of macular degeneration using embryonic stem cell-derived retinal pigmentepithelium: preliminary results in Asian patients. Stem Cell Reports. 2015; 4:860-872.

21. [Internet] Assistance Publique - Hôpitaux de Paris. Transplantation of Human Embryonic Stem Cell-derived Progenitors in Severe Heart Failure [ESCORT] Available at https://www.clinicaltrials.gov/ct2/show/NCT02057900.

22. ViaCyte. A Safety, Tolerability, and Efficacy Study of VC-01 $01^{\mathrm{TM}}$ Combination Product in Subjects With Type I Diabetes Mellitus. U.S. National Institute of Health 2015.

23. Meyer JR. The significance of induced pluripotent stem cells for basic research and clinical therapy. J Med Ethics. 2008; 34:849-851.

24. Takahashi $\mathrm{K}$ and Yamanaka S. Induction of pluripotent stem cells from mouse embryonic and adult fibroblast cultures by defined factors. Cell. 2006; 126:663-676

25. Ghaedi M and Niklason LE. Human Pluripotent Stem Cells [iPSC] Generation, Culture, and Differentiation to Lung Progenitor Cells. Methods Mol Biol. 2016; [Epub ahead of print].

26. Mathews DJ, Donovan PJ, Harris J, et al. Pluripotent stem cell-derived gametes: truth and [potential] consequences. Cell Stem Cell. 2009; 5:11-14.

27. Wernig M, Zhao JP, Pruszak J, et al. Neurons derived from reprogrammed fibroblasts functionally integrate into the fetal brain and improve symptoms of rats with Parkinson's disease. Proc Natl Acad Sci U S A. 2008; 105:5856-5861.

28. Kiskinis E and Eggan K. Progress toward the clinical application of patient-specific pluripotent stem cells. J Clin Invest. 2010; 120:51-59.

29. Yoshihara M, Hayashizaki Y, Murakawa Y. Genomic Instability of iPSCs: Challenges Towards Their Clinical Applications. Stem Cell Rev. 2017; 13:7-16.

30. Gore A, Li Z, Fung HL, et al. Somatic coding mutations in human induced pluripotent stem cells. Nature. 2011; 471:63-67.

31. Ji J, Ng SH, Sharma V, et al. Elevated coding mutation rate during the reprogramming of human somatic cells into induced pluripotent stem cells. Stem Cells. 2012; 30:435-440.

32. Liang $G$ and Zhang Y. Genetic and epigenetic variations in iPSCs: potential causes and implications for application. Cell Stem Cell. 2013; 13:149-159.

33. Blasco MA, Serrano M, Fernandez-Capetillo O. Genomic instability in iPS: time for a break. EMBO J. 2011; 30:991-993.

34. Bock C, Kiskinis E, Verstappen G, et al. Reference Maps of human ES and iPS cell variation enable high-throughput characterization of pluripotent cell lines. Cell. 2011; 144:439-452.

35. Mandai $M$ Watanabe $A$ Kurimoto $Y$ et al Autologous Induced Stem-Cell-Derived Retinal Cells for Macular Degeneration. N Engl J Med. 2017; 376:1038-1046.

36. Feng $\mathrm{B}, \mathrm{Ng} \mathrm{JH}$, Heng $\mathrm{JC}, \mathrm{Ng} \mathrm{HH}$. Molecules that promote or enhance reprogramming of somatic cells to induced pluripotent stem cells. Cell Stem Cell. 2009; 4:301-312.
37. Stadtfeld M, Nagaya M, Utikal J, et al. Induced pluripotent stem cells generated without viral integration. Science. 2008; 322:945-949.

38. Okita K, Nakagawa M, Hyenjong $H$, et al. Generation of mouse induced pluripotent stem cells without viral vectors. Science. 2008; 322:949-953.

39. Soldner F, Hockemeyer D, Beard C, et al. Parkinson's disease patient-derived induced pluripotent stem cells free of viral reprogramming factors. Cell. 2009; 136:964-977.

40. Plath $\mathrm{K}$ and Lowry WE. Progress in understanding reprogramming to the induced pluripotent state. Nat Rev Genet. 2011; 12:253-265.

41. Woltjen $\mathrm{K}$, Michael IP, Mohseni $\mathrm{P}$, et al. piggyBac transposition reprograms fibroblasts to induced pluripotent stem cells. Nature. 2009; 458:766-770.

42. Volarevic V, Al-Qahtani A, Arsenijevic N, et al. Interleukin-1 receptor antagonist [IL-1Ra] and IL-1Ra producing mesenchymal stem cells as modulators of diabetogenesis. Autoimmunity. 2010; 43:255-263.

43. Dominici M, Le Blanc K, Mueller I, et al. Minimal criteria for defining multipotent mesenchymal stromal cells. The International Society for Cellular Therapy position statement. Cytotherapy. 2006; 8:315-317.

44. Pittenger MF, Mackay AM, Beck SC, et al. Multilineagepotential of adult human mesenchymal stem cells. Science. 1999; 284:143-147.

45. Lee JH, Chang HS, Kang EH, et al. Percutaneous transplantation of human umbilical cord blood-derived multipotent stem cells in a canine model of spinal cord injury. J Neurosurg Spine. 2009; 11:749-757.

46. Park DH, Lee JH, Borlongan CV, et al. Transplantation of umbilical cord blood stem cells for treating spinal cord injury. Stem Cell Rev Rep. 2011; 7:181-194.

47. Kang XQ, Zang WJ, Bao LJ, et al. Fibroblast growth factor-4 and hepatocyte growth factor induce differentiation of human umbilical cord blood-derived mesenchymal stem cells into hepatocytes. World J Gastroenterol. 2005; 11:7461-7465.

48. Gebler A, Zabel O, Seliger B. The immunomodulatory capacity of mesenchymal stem cells. Trends Mol Med. 2012; 18:128-134.

49. Li W, Ren G, Huang Y, et al. Mesenchymal stem cells: a double-edged sword in regulating immune responses. Cell Death Differ. 2012; 19:1505-1513.

50. Morandi F, Raffaghello L, Bianchi G, et al. Immunogenicity of Human Mesenchymal Stem Cells in HLA-Class I-Restricted T-Cell Responses Against Viral or Tumor-Associated Antigens. Stem Cells. 2008; 26:1275-1287.

51. Ciccocioppo R, Bernardo ME, Sgarella A, et al. Autologous bone marrow-derived mesenchymal stromal cells in the treatment of fistulising Crohn's disease. Gut. 2011; 60:788-798.

52. Molendijk I, Bonsing BA, Roelofs H, et al. Allogeneic Bone Marrow-Derived Mesenchymal Stromal Cells Promote Healing of Refractory Perianal Fistulas in Patients With Crohn's Disease. Gastroenterology. 2015; 149:918-927.

53. Lee WY, Park KJ, Cho YB, et al. Autologous adipose tissue-derived stem cells treatment demonstrated favorable and sustainable therapeutic effect for Crohn's fistula. Stem Cells. 2013; 31: 2575-2581.

54. Cho YB, Lee WY, Park KJ, et al. Autologous adipose tissue-derived stem cells for the treatment of Crohn's fistula: a phase I clinical study. Cell Transplant. 2013; 22: 279-285.

55. Panés J, García-Olmo D, Van Assche G, et al. Expanded allogeneic adipose-derived mesenchymal stem cells [Cx601] for complex perianal fistulas in Crohn's disease: a phase 3 randomised, double-blind controlled trial. Lancet. 2016; 388:1281-1290.

56. Duijvestein M, Vos AC, Roelofs $\mathrm{H}$, et al. Autologous bone marrow derived mesenchymal stromal cell treatment for refractory luminal Crohn's disease: results of a phase I study. Gut. 2010; 59:1662-1669.

57. Dhere $\mathrm{T}$, Copland I, Garcia $\mathrm{M}$, et al. The safety of autologous and metabolically fit bone marrow mesenchymal stromal cells in medically refractory Crohn's disease - a phase 1 trial with three doses. Aliment Pharmacol Ther. 2016; 44:471-481.

58. Pfizer, Athersys Inc. A Study to Investigate the Safety and Possible Clinical Benefit of Multistem ${ }^{\circledR}$ in Patients with Moderate to Severe UlcerativeColitis. 2014.

59. Gazdic M, Volarevic V, Arsenijevic N, Stojkovic M. Mesenchymal stem cells: a friend or foe in immune-mediated diseases. Stem Cell Rev. 2015; 11:280-287.

60. Kharaziha P, Hellström PM, Noorinayer B, et al. Improvement of liver function in liver cirrhosis patients after autologous mesenchymal stem cell injection: a phase I-II clinical trial. Eur J Gastroenterol Hepatol. 2009; 21:1199-1205.

61. Amer ME, El-Sayed SZ, El-Kheir WA, et al. Clinical and laboratory evaluation of patients with end-stage liver cell failure injected with bone marrow-derived hepatocyte-like cells. Eur J Gastroenterol Hepatol. 2011; 23:936-941.

62. Peng L, Xie DY, Lin BL, et al. Autologous bone marrow mesenchymal stem cell transplantation in liver failure patients caused by hepatitis B: shortterm and long-term outcomes. Hepatology. 2011; 54:820-828.

63. Amin MA, Sabry D, Rashed LA, et al. Short-term evaluation of autologous transplantation of bone marrow-derived mesenchymal stem cells in patients with cirrhosis: Egyptian study. Clin Transplant. 2013; 27:607-612.

64. Zhang Z, Lin H, Shi M, et al. Human umbilical cord mesenchymal stem cells improve liver function and ascites in decompensated liver cirrhosis patients. J Gastroenterol Hepatol. 2012; 27 (Suppl 2):S112-S120.

65. Shi M, Zhang Z, Xu R, et al. Human mesenchymal stem cell transfusion is safe and improves liver function in acuteon-chronic liver failure patients. Stem Cells Transl Med. 2012; 1:725-731.

66. Hare JM, Traverse $\mathrm{JH}$, Henry $\mathrm{TD}$, et al. A randomized, double-blind, placebo-controlled, dose-escalation study of intravenous adult human 
mesenchymal stem cells [prochymal] after acute myocardial infarction. J Am Coll Cardiol. 2009; 54:2277-2286.

67. Chen SL, Fang WW, Ye F, et al. Effect on left ventricular function of intracoronary transplantation of autologous bone marrow mesenchymal stem cell in patients with acute myocardial infarction. Am J Cardiol. 2004; 94:92-95.

68. Bartunek J, Behfar A, Dolatabadi D, et al. Cardiopoietic stem cell therapy in heart failure: the C-CURE [Cardiopoietic stem Cell therapy in heart failURE] multicenter randomized trial with lineage-specified biologics. J Am Coll Cardiol. 2013; 61:2329-2338.

69. Katritsis DG, Sotiropoulou P, Giazitzoglou E, et al. Electrophysiological effects of intracoronary transplantation of autologous mesenchymal and endothelial progenitor cells. Europace. 2007; 9:167-171

70. Haack-Sørensen M, Friis $\mathrm{T}$, Mathiasen $\mathrm{AB}$, et al. Direct intramyocardial mesenchymal stromal cell injections in patients with severe refractory angina: one-year follow-up. Cell Transplant. 2013; 22:521-528.

71. Breitbach M, Bostani T, Roell W, et al. Potential risks of bone marrow cell transplantation into infarcted hearts. Blood. 2007; 110:1362-1369.

72. Yoon YS, Park JS, Tkebuchava T, et al. Unexpected severe calcification after transplantation of bone marrow cells in acute myocardial infarction. Circulation. 2004; 109:3154-3157.

73. Kuriyan AE, Albini TA, Townsend JH, et al. Vision Loss after Intravitreal Injection of Autologous "Stem Cells" for AMD. N Engl J Med. 2017; 376:1047-1053.

74. Lazennec and Jorgensen C. Concise review: adult multipotent stromal cells and cancer: risk or benefit? Stem Cells. 2008; 26:1387-1394.

75. Patel SA, Meyer JR, Greco SJ, et al. Mesenchymal stem cells protect breast cancer cells through regulatory $\mathrm{T}$ cells: role of mesenchymal stem cell-derived TGF-beta. J Immunol. 2010; 184:5885-5894.

76. Wang X, Zhang Z, Yao C. Survivin is upregulated in myeloma cell lines cocultured with mesenchymal stem cells. Leuk Res. 2010; 34:1325-1329.

77. Ljujic B, Milovanovic M, Volarevic V, et al. Human mesenchymal stem cells creating an immunosuppressive environment and promote breast cancer in mice. Sci Rep. 2013; 3:2298.

78. Oswald J, Boxberger S, Jørgensen B et al. Mesenchymal stem cells can be differentiated into endothelial cells in vitro. Stem Cells. 2004; 22:377-384.

79. Janeczek Portalska K, Leferink A, Groen N, et al. Endothelial differentiation of mesenchymal stromal cells. PLoS One. 2012; 7:e46842.

80. Khakoo AY, Pati S, Anderson SA, et al. Human mesenchymal stem cells exert potent antitumorigenic effects in a model of Kaposi's sarcoma. J Exp Med. 2006; 203:1235-1247. 